\title{
The Effect of Members Participation on Business Self-Reliance and MembersWelfare(Study on Cooperative Corporation in East Java Indonesia)
}

\author{
Kadarisman Hidayat, Suharyono, Srikandi Kumadji, Solimun \\ ${ }_{1,2,3,4}$ Brawijaya University, Indonesia
}

\begin{abstract}
The purpose ofthis study was to examine and explain the effect of members participation on business self-reliance and members welfare. The study was conducted in a cooperative corporation that operates in the region of East Java Indonesia. The respondents were 156 cooperative enterprise members. Data were analyzed using the GSCA approach (Generalized Structural Component Analysis). The results showed that the Members Participation significant effect on business self-reliance and members welfare and business self-reliance also have a significant effect on the welfare member. Other findings indicate that membership in the cooperative corporation as the owner and customers of the cooperative enterprise. Therefore, companies should pay attention to the needs of cooperative members.
\end{abstract}

Keywords:members participation, business self-reliance, members welfare, cooperative corporation.

\section{Introduction}

The existence of cooperatives is generally understood as a voluntary association of people who unite themselves to fight for the improvement of economic welfare member, through the establishment of a business entity that is managed democratically. Cooperative Company is a popular and suitable economic institutions developed in Indonesia because according to the spirit of Indonesian society (Wijaya, 2002). However, the company is a form of cooperative business generally lags compared to other businesses such as private companies and State Owned Enterprises (SOEs), especially in terms of increased economic efficiency (Ropke, 2000). sluggish business growth rate (Wijaya, 2002), identical to the micro, small and medium enterprises (Kuncoro, 2000).

Corporate cooperative economy is a dynamic institution and carried out in accordance with the potential and comparative advantages. Cooperative enterprises in Indonesia is growing rapidly even in conditions of economic crisis. This is a proof that the cooperative enterprise can survive and even thrive in the economic crisis and high competition. There are several activities that develop cooperative enterprises in Indonesia include savings and loans or credit unions, consumer cooperatives, marketing cooperatives and producer cooperatives. Cooperative enterprise proven to survive in the world and the situation of the national economic crisis was still not satisfactory as a pillar in order to achieve economic justice and social welfare of the community. The reason is the low participation of members. The low participation of cooperative members and the co-operative does not have the advantage (Ropke, 1989). As a result, the benefit (benefit) perceived cooperative members also low (Hazen, 1999).

Actually, at the Company's Cooperative, member participation is a critical variable in determining the success of a cooperative (Gray \& Butler, 1991; Nirbito, 2001). Meanwhile Harkelius (1996) states "Members participation in cooperative has always been an important issues, Because members are a vital part of any cooperative organization and their active participation in and loyalty to a cooperative business is integral for the success of the cooperative". Members of the cooperative part of the main organs in the cooperative organization. Their active participation and loyalty is key to the success of the organization include poverty eradication, employment creation and social integration and productivity improvement.

\section{Membersparticipation}

\section{Theoretical review}

Participationliterally meanstakingpartorinclusion(Echols, 2003). Siswoyo(2004) defines participation as how far the level of involvement of members in the form of contribution of financial resources (the fulfillment of members' savings, and cooperative capital requirements), decision making (planning, implementation or execution and evaluation) and in the form of incentives or user benef it of the services of the cooperative. Hanel(1985) stated that the cooperative has four characteristics as shown in Figure1. 


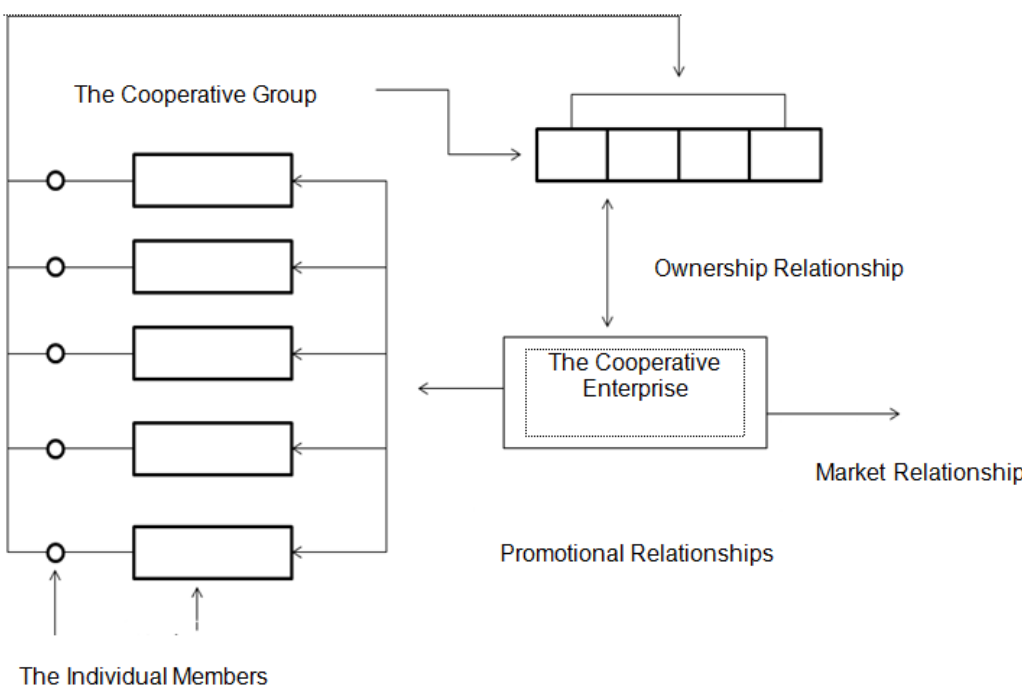

Figure1.Cooperative Organization for Socio-Economic System.(Hanel.1985:34)

It can be specified as a cooperative characteristics of the socio-economic system, namely: 1) A number of individuals who are united in a group on the basis of at least one common interest or goal(cooperative group). 2) Cooperative group members individually determined to realize the goal of improving their economic and social situation, through joint efforts and mutual aid (non-cooperative group). 3) As an instrument to realize it is acompany owned and nurtured together (cooperative enterprise). 4) The cooperative company assigned to supportthe interests of its members by providing a cooperative group or offer goods and services required by the members for economic activity, ie the company (farm, business unit, and a variety of other businesses) and or individual household members (member promotional purposes or principles).

Based on the scheme of Figure 1, the cooperative organization is a socio-economic system that is composed of sub-systems, such as: (1) individual members and their economic activities (household or corporate members), (2) cooperative group (cooperative group), (3) cooperative companies (cooperative enterprise). All the sub-systems that are interconnected internal relationships. Another characteristic of the cooperative organization is "the persons who own them (The shareholders, the investors), the persons who control them (the effective decision markers) and the persons who use them (the customers)". Further stated "In cooperative, all three come together to form a unity, those who own, those who control, and those who use are one" (Dogarawa.2005). Thus it can be called a cooperative if the owner, supervisor and users are the same people within the organization.

Participation cannot be is assumed as the 'given' or something that happens automatically in the presence of cooperative (Ropke, 2000). Member participation in this study is measured by several indicators, among others, participation in loans, participation in deposit / savings, participation in loan repayment, equity participation, and participation in the decision determining the annual meeting of members.

\section{Business Self-Reliance}

Turning cooperative manner to manage a variety of business activities that may result in benefits for the individual members and the cooperative can also be classified as part of the running process of development economics . In addition to the field of economic development, also known as human development . Human development is expected to further improve the welfare of human life, and independence (self - empowerment) on an ongoing basis. The recommendations of the 90th Session of the ILO in Geneva in 2002 which have helped establish the identity of the cooperative and expressed confidence that cooperation can contribute in creating decent jobs and human (decent employment). The statement implies that the success of cooperative efforts related to empowerment or independence of memberbusinesses.

\section{Members Welfare}

Cooperative effort and welfare are two important elements in realizing the ideals of establishing a cooperative business (Ropke, 2000). Welfare is a reflection of the goals to be achieved in every establishment of cooperative enterprise. it means the property owned by the cooperative and its set of institutional factors will be used as much as possible for prosperity (promotion) of its members (Hanel, 1985). On the other hand, the welfare of members can be realized because of the relationship between owners who act as well as customers, suppliers, consumers, and employees (Ropke, 2000) 
Individual welfare levels associated with the level of satisfaction (utility) and the pleasures that can be achieved by an individual in accordance with the limitations. These limitations can be due to income and resource availability. UN resolution number 54/123 and 56/114 of 2001 emphasized that cooperatives have a role in poverty eradication, full employment and social integration and increased productive. Thus the success of the cooperative will be oriented towards the achievement of the welfare of its members. In achieving the desired level of welfare by individual, certain behaviors and actions required to maximize the satisfaction level of the individual in accordance with the existing resources in the economy. In this study welfare member is measured by indicators such as real income members, level of education, health, savings, and feel safe and comfortable.

\section{Researchproposition}

Based on theexplanationin the introductionand review oftheories, propositionspresentedin this research include: P1: Participation of members have an influence on the Business Self-Reliance

P2: Business Self-Reliance have an influence on the Members welfare.

P3: Participation of members have an influence on the Members welfare.

\section{Research Methodology}

The sample in this study are members of cooperatives as many as 156 cooperative enterprise members, with the sampling method using accidental sampling. In this study, the instrument used a questionnaire, which has been prepared using a Likert Scale. Likert scale in this study using five levels, namely strongly disagree, disagree, undecided, agree and strongly agree. Questionnaire consists of 19 items on Member Participation, 9 items on the Business Self-Relianceand 19 items in the Members welfare. Detailed questionnaire of this study can be found in appendix1. Data were analyzed by using the GSCA to answer the research hypothesis (Hwang 2009, 2010).

\section{Measure of fit Structural Model}

\section{Result}

Goodness of fit test indicated FIT value is equal to 0.476. and AFIT (Adjusted FIT) is 0.468. Thus, the model can explain all the variables formed there by 47.6 percent. This model is quite good, because nearly $50 \%$ could explain the variability of the data.Further, the GFIvalueis equal to0.999, indicating that the overall model is very good, approaching the cut-off value of $\geq 0.90$. While the SRMR value equal to0.096, which indicates that the overall model is very good.

Table1 Goodness of Fit

\begin{tabular}{|c|c|}
\hline \multicolumn{2}{|c|}{ Model Fit } \\
\hline FIT & 0.476 \\
\hline AFIT & 0.468 \\
\hline GFI & 0.999 \\
\hline SRMR & 0.096 \\
\hline
\end{tabular}

\section{Measurement Indicators}

The measurement results of research indicators in Table 2 indicate that the validity and reliability is good enough.

Table 2. Measurement Indicators

\begin{tabular}{|c|c|c|c|}
\hline \multirow{2}{*}{ Construct } & \multicolumn{3}{|c|}{ Loading } \\
\cline { 2 - 4 } & Estimate & SE & CR \\
\hline Participation & & & $7,06^{*}$ \\
\hline X.1 & 0,547 & 0,077 & $10,4^{*}$ \\
\hline X.2 & 0,716 & 0,069 & $8,94^{*}$ \\
\hline X.3 & 0,627 & 0,070 & $16,03^{*}$ \\
\hline X.4 & 0,768 & 0,048 & $9,82^{*}$ \\
\hline $\mathbf{X . 5}$ & 0,722 & 0,074 & $28,17^{*}$ \\
\hline $\mathbf{X . 6}$ & 0,853 & 0,030 & $9,04^{*}$ \\
\hline $\mathbf{X . 7}$ & 0,542 & 0,060 & $18,39^{*}$ \\
\hline $\mathbf{X . 8}$ & 0,801 & 0,044 & $16,35^{*}$ \\
\hline $\mathbf{X . 9}$ & 0,811 & 0,050 & $18,64^{*}$ \\
\hline $\mathbf{X . 1 0}$ & 0,775 & 0,042 & $12,13^{*}$ \\
\hline $\mathbf{X . 1 1}$ & 0,723 & 0,060 & $11,38^{*}$ \\
\hline $\mathbf{X . 1 2}$ & 0,732 & 0,064 & \\
\hline
\end{tabular}


The Effect of Members Participation on Business Self-Reliance and Members Welfare .....

\begin{tabular}{|l|l|l|l|}
\hline $\mathbf{X . 1 3}$ & 0,552 & 0,104 & $5,32^{*}$ \\
\hline $\mathbf{X . 1 4}$ & 0,559 & 0,104 & $5,39^{*}$ \\
\hline $\mathbf{X . 1 5}$ & 0,581 & 0,098 & $5,92^{*}$ \\
\hline $\mathbf{X . 1 6}$ & 0,734 & 0,065 & $11,25^{*}$ \\
\hline $\mathbf{X . 1 7}$ & 0,709 & 0,090 & $7,88^{*}$ \\
\hline $\mathbf{X . 1 8}$ & 0,765 & 0,039 & $19,81^{*}$ \\
\hline $\mathbf{X . 1 9}$ & 0,784 & 0,059 & $13,32^{*}$ \\
\hline & \multicolumn{3}{|c|}{$\mathbf{A V E}=\mathbf{0 . 5 0 0}$, Alpha $=\mathbf{0 . 9 4 1}$} \\
\hline
\end{tabular}

\begin{tabular}{|c|c|c|c|}
\hline \multirow{2}{*}{ Construct } & \multicolumn{3}{|c|}{ Loading } \\
\cline { 2 - 4 } & Estimate & SE & CR \\
\hline Business Self-Reliance & & & $10,28^{*}$ \\
\hline Y.1 & 0,618 & 0,060 & $15,24^{*}$ \\
\hline Y.2 & 0,752 & 0,049 & $16,86^{*}$ \\
\hline Y.3 & 0,748 & 0,044 & $15,58^{*}$ \\
\hline Y.4 & 0,718 & 0,046 & $19,52^{*}$ \\
\hline Y.5 & 0,804 & 0,041 & $13,29^{*}$ \\
\hline Y.6 & 0,747 & 0,056 & $30,45^{*}$ \\
\hline Y.7 & 0,841 & 0,028 & $18,24^{*}$ \\
\hline Y.8 & 0,816 & 0,045 & $12,74^{*}$ \\
\hline Y.9 & 0,753 & 0,059 & \\
\hline
\end{tabular}

\begin{tabular}{|c|c|c|c|}
\hline \multirow[t]{2}{*}{ Construct } & \multicolumn{3}{|c|}{ Loading } \\
\hline & Estimate & $S E$ & $C R$ \\
\hline \multicolumn{4}{|l|}{ Members Welfare } \\
\hline Z.1 & 0,627 & 0,077 & $8,82 *$ \\
\hline $\mathrm{Z.2}$ & 0,731 & 0,056 & $13,12 *$ \\
\hline Z.3 & 0,703 & 0,053 & $13,25^{*}$ \\
\hline Z.4 & 0,790 & 0,048 & $16,36^{*}$ \\
\hline Z.5 & 0,833 & 0,046 & $18,14^{*}$ \\
\hline Z.6 & 0,781 & 0,069 & $11,34^{*}$ \\
\hline Z.7 & 0,806 & 0,056 & $14,44 *$ \\
\hline Z.8 & 0,647 & 0,067 & $9,6^{*}$ \\
\hline Z.9 & 0,389 & 0,111 & $3,51 *$ \\
\hline Z.10 & 0,334 & 0,118 & $2,83^{*}$ \\
\hline Z.11 & 0,385 & 0,118 & $3,26^{*}$ \\
\hline Z.12 & 0,663 & 0,074 & $8,94 *$ \\
\hline Z.13 & 0,644 & 0,075 & $8,56^{*}$ \\
\hline Z.14 & 0,673 & 0,059 & $11,44^{*}$ \\
\hline Z.15 & 0,729 & 0,054 & $13,48^{*}$ \\
\hline Z.16 & 0,739 & 0,065 & $11,37^{*}$ \\
\hline $\mathrm{Z.17}$ & 0,652 & 0,081 & $8,04 *$ \\
\hline Z.18 & 0,455 & 0,063 & $7,27 *$ \\
\hline \multirow[t]{2}{*}{ Z.19 } & 0,453 & 0,102 & $4,45^{*}$ \\
\hline & \multicolumn{3}{|c|}{ AVE $=0.424$, Alpha $=0.91$} \\
\hline
\end{tabular}

$\mathrm{CR}^{*}=$ significant at .05 level

The proposition test each path of this research can be seen in Figure 1 below. 


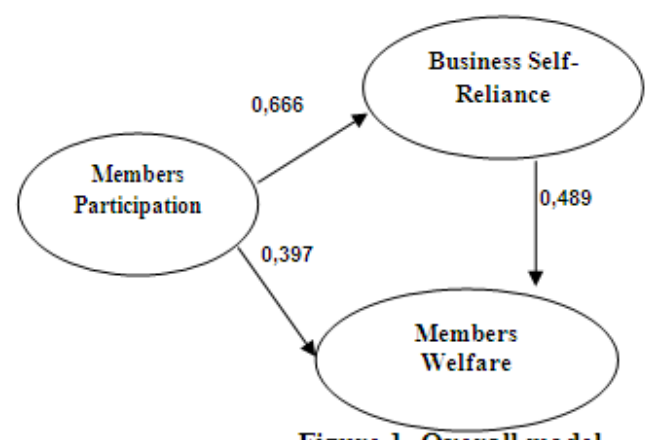

Figure 1. Overall model.

Table 3. Path Coefficients

\begin{tabular}{|l|c|c|c|}
\hline \multicolumn{4}{|c|}{ Path Coefficients } \\
\hline Participation ->Business Self-Reliance & Estimate & SE & CR \\
\hline Participation -> Welfare member & 0.666 & 0.063 & $10.53^{*}$ \\
\hline Business Self-Reliance -> Welfare member & 0.397 & 0.081 & $4.89^{*}$ \\
\hline
\end{tabular}

\section{P1: The effect ofparticipationon thebusinessof self-reliance}

Member participation variables directly influence the business of self-reliance is 0.666 (SE 0.063). statistically proven that participation has a positive and significant impact on the business of self-reliance. This means that the higher the Member's participation will result in a business self-reliance.

\section{P2: The effect of business self-reliance onmemberwelfare}

Business self-reliance has a positive and significant influence on welfare member. The coefficientis 0.397 (SE 0.081). This means that the higher the business self reliance in turn will result in higher on welfare member.

\section{P3: The effect of MemberParticipationinfluenceonWelfare member}

Member participation has a positive and significant impact on theWelfare member. Path coefficient is equal to 0.489 (SE 0.070). This means that the higher the Member Participation will lead to higher theWelfare member.

\section{Conclusion and Discussion}

The results of this study states that Member participation has a positive influence on the business of self-reliance. Business self-reliance is formed from the active involvement of members. The active involvement of the members can be done in the form of capital investment, participation in decision-making, product development, and culture of putting the interests of members. The active participation of cooperative members conducting business transactions will strengthen the business of self-reliance.

Business self-reliance effect on welfare member. The independence of members in the perspective of cooperative efforts have the broadest sense. The desire of members to strengthen business networks starting from the spirit of brotherhood among the members. Demand for goods and services is always done in business activities within the cooperative. This means that the trading behavior of members to members are hallmarks of the company's cooperation. Furthermore, the stronger the business of self-reliance will increase transaction activity that will ultimately have an impact on the welfare of members. Business self-reliance effect on welfare member. The independence of membersin the perspective of cooperative efforts have the broadest sense. The desire of members to strengthen business networks starting from the spirit of brotherhood among the members. Demand for goods and services is always done in business activities within the cooperative. This means that the trading behavior of members to members are hallmarks of the company's cooperation. Furthermore, the stronger the business of self-reliance will increase transaction activity that will ultimately have an impact on the welfare of members.

The study's finding sare consistent with the theory of economic development that independence in the operations related to well-being. Independence of members of the cooperative effort to trigger more creative and innovative in developing the business. Cooperative leadership should increase the motivation of its members to increase participation. Along with the increasing participation of members of the business self-reliance and members welfare will be more likely to be realized. 
Furthermore, there are differences between the characteristics of the organization of cooperatives with other business organizations. Cooperative organizations are more inclined family spirit. This understanding must always be understood by members to the stronger cohesiveness among members.

Characteristics of participatory management needs to understand the cooperative members as a form of togetherness, openness and mutual trust so that every member of both involved in the management (cooperative management) or are outside the management (regular member) who has a sense of shared responsibility.

In the future, members of co-operatives need to educate other potential members that the cooperative as a forum for the development and improvement of the welfare of members. In addition, the cooperative organization can be viewed as "member-based association" (association of persons), with collective traits, "user-driven", is motivated by maximization of quality of service.

As one of the pillars of the economy, the government should give attention to the cooperative as a democratic economic institutions in accordance with Indonesian culture. Cooperative organizations are expected to play an active role in the national economy and can be a balancing power (countervailing power) against forms of market mechanisms such as the free market. Past experience showed in a crisis situation, relatively cooperative organization can survive compared to the private sector and SOEs. The government needs to educate the public sustained, that are interested in forming a business organization such as cooperatives.

In order to empower the function and role of cooperatives, government intervention is necessary in order to improve the profitability of cooperative members. Access to finance such as loans from banks, both from within and outside the country needed in order to improve the capacity and capability of the cooperative organization.

\section{Reference}

[1]. Dogarawa, Ahmad Bello, 2005, The Role of Cooperative Societies in Economic Development, Ahmadu Bello University, ZariaNigeria.

[2]. Echols, John M., and Hassan Shadily. , 2003. Indonesian English Dictionary, An English-Indonesian Dictionary. Publisher PT. Gramedia. Jakarta. Indonesia

[3]. Gray, T.W. \& Buttler, G. 1991. Charting form Within a Grounded Concept of Member Control. Journal of Agricultural Cooperation, Vol.6, pp. 82-93

[4]. Harkelius, Karin dalam Laursen, Christin V.; Kostas Karantiminis; Sanjib Bhuyan. 2008. Organizational Characteristics and Member Participation in Agricultural Cooperatives: Evidence from Modern Dhanish Cooperatives. Paper Submitted to the Seminar: The Role of the Cooperative in The European. Agro-food System May 28-30th, 2008. Bologna.

[5]. Hanel, Alfred. 1985. Basic Aspect of Cooperative Organization and Policies for Their Promotion in Developing Countries, Universitas Padjadjaran, Bandung. Indonesia.

[6]. Hazen, Paul. 1999. Adding Value to Membership, NewForm of Cooperative Business in The United States; National cooperative Business Assosiation. 1401 New York Avc., N.W. Washington. D.C.

[7]. Helm, F.C.1968. The Economics of cooperative Enterprise. University of London Press Ltd., London.

[8]. Hwang, H.2009. Regularized Generalized Structured Component Analysis. Psychometrika. Vol 70. No 3. P 517-530

[9]. Hwang, H., M.R. Ho, and J. Lee. 2010. Generalized Structured Component Analysis with Latent Interactions. Psychometrika. Vol 75 No 2. P $228-242$

[10]. Kuncoro, Mudrajat. 2000. Small Business In Indonesia: Profile, Problems and Strategies Empowerment. http://www.Adobe.Com/Products/DigitaleditionsSourceacromenu Retrieved on November 3, 2007.

[11]. Nirbito, J.G. 2001. Coaching to Empower Cooperative Members in East Java. Dissertation, Graduate University of Malang. Indonesia.

[12]. Ropke, Jochen.1989. The Economic Theory of Cooperatives. Marburg. Germany.

[13]. - -

[14]. Ropke, Jochen. 2000. The Economic Theory Of Cooperative. Salemba Empat. Jakarta. Indonesia.

[15]. Siswoyo. Bambang Banu. 2004. Cooperative Members Organizational Behavior and Impact on Member Participation And Benefits Provided by Cooperative Members, the Dissertation. Brawijaya University doctoral program. Malang. Indonesia

[16]. Wijaya, N.H.Seriadi. 2002.WakingfromdreamspoorCooperative. IndonesianEntrepreneurManagement, No. 07pp. 28-34. 
Apendix 1.

Construct and Indicators

\begin{tabular}{|c|c|}
\hline Construct & Indicators \\
\hline Member Participation & 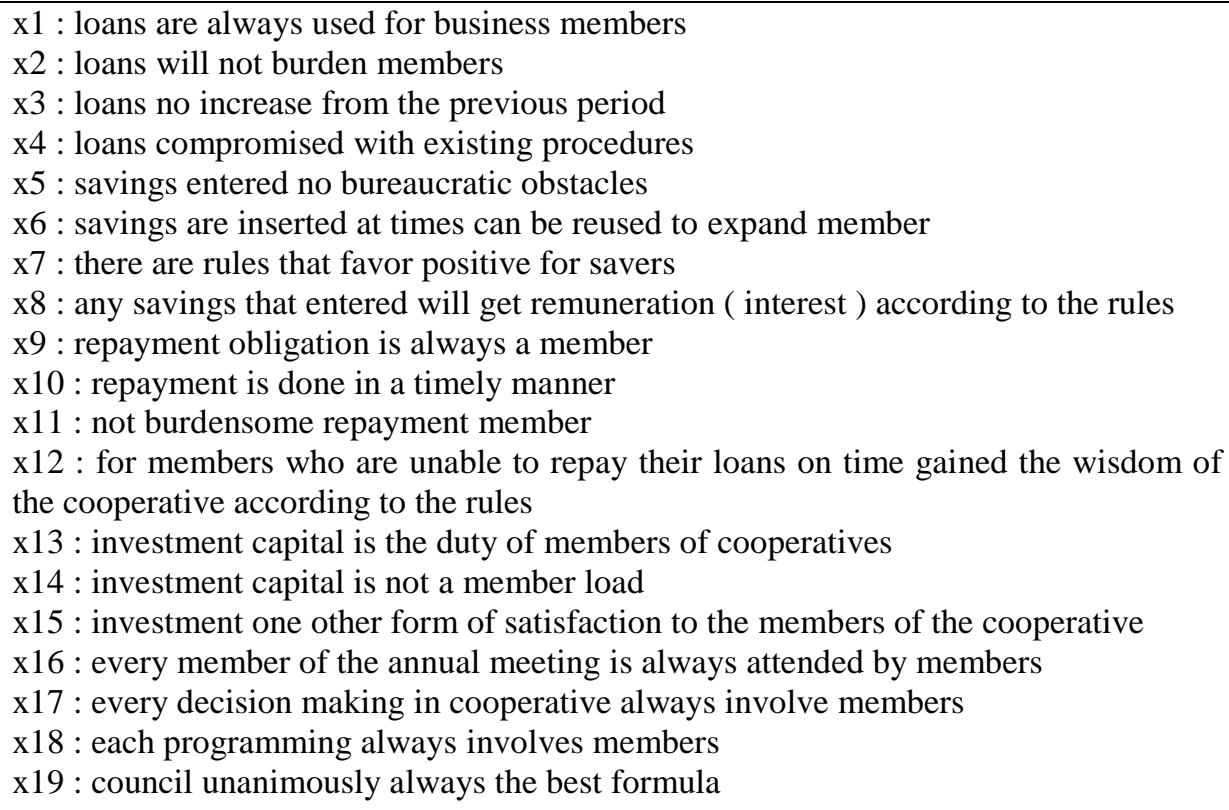 \\
\hline $\begin{array}{l}\text { Business Self- } \\
\text { Reliance }\end{array}$ & $\begin{array}{l}\text { y1: venture capital always adequately met from cooperative } \\
\text { y2: venture capital easily perceived as a member of the cooperative } \\
\text { y3: i think if you reduce the participation of the cooperative will also reduce the } \\
\text { independence of her capital } \\
\text { y4: the opportunity to increase market share from the previous period } \\
\text { y5: chance increased market share possessed of almost all existing businesses } \\
\text { y6: i think if you reduce the cooperative participation will reduce also in increasing its } \\
\text { market opportunities } \\
\text { y7: business opportunities for members } \\
\text { y8: business opportunities in various business } \\
\text { y9: if reducing the participation of the cooperative will also reduce the chance of doing } \\
\text { business increase }\end{array}$ \\
\hline Members Welfare & $\begin{array}{l}\text { z1: revenue received increased from the previous period } \\
\text { z2: basic needs of each family member can be provided } \\
\text { z3: there are advantages of regular monthly expenditure } \\
\text { z4: the level of education of children who achieved always guaranteed } \\
\text { z5: beneficial education on how to improve your business knowledge } \\
\text { z6: education is always beneficial to the environment surrounding communities } \\
\text { z7: each additional beneficial for family life education } \\
\text { z8: the health check is always performed routinely member } \\
\text { z9: the medical examination of all family members have always done routine } \\
\text { z10: obtaining health care something that is easy } \\
\text { z11: every health complaints quickly to health services } \\
\text { z12: ownership of savings is a family obligation } \\
\text { z13: increased effort partly from savings } \\
\text { z14: the use of family recreation seagian obtained from savings } \\
\text { z15: shopping unexpected aside from the savings } \\
\text { z16: can rest in peace } \\
\text { z17: the house is located in a quiet neighborhood } \\
\text { z18: enjoy free time with sufficient } \\
\text { z19: households run harmoniously }\end{array}$ \\
\hline
\end{tabular}

